\title{
Discussion on the Integrated Financing Mode of EMC and Carbon Trading
}

\author{
Ying Qin', Hongchun Wang1, Kai Wang1, Zeyu Li ${ }^{2}$ \\ ${ }^{1}$ Beijing University of Civil Engineering and Architecture, Beijing, China \\ ${ }^{2}$ Canvard College, Beijing Technology and Business University, Beijing, China \\ Email: qinying166@163.com, wanghongchun@bucea.edu.cn, 328682573@qq.com
}

Received 4 July 2014; revised 4 August 2014; accepted 1 September 2014

Copyright (C) 2014 by authors and Scientific Research Publishing Inc.

This work is licensed under the Creative Commons Attribution International License (CC BY).

http://creativecommons.org/licenses/by/4.0/

c) (i) Open Access

\begin{abstract}
EMC (energy management contract) is a recognized energy-saving innovation pattern of technology, financing and management. But because of the consciousness problems, legal issues and policy oriented issues, EMC project has a series of problems. The financing difficulty is one of the main problems, which has seriously affected the sustainable development of energy service industry. Carbon trading is an arrangement of new carbon emission reduction system. If the EMC project is embedded into the carbon trading, it will realize the organic integration of contract energy management and carbon emission reduction. Not only can it make carbon trading market mechanism active, but also solve the bottleneck problem of EMC. This study attempts to construct financing mode of EMC and carbon emission combination to solve the difficult problem of financing contract energy and carbon trading inactive problem.
\end{abstract}

\section{Keywords}

Energy Management Contract, Carbon Trading, Carbon Rights

\section{Introduction}

Environmental pollution and resource shortage has become a bottleneck restricting China's economic development, energy saving and emission reduction in China has reached a critical stage. Especially in recent years the problem of air pollution and continuous detonation point of PM 2.5 has sounded the alarm to energy conservation and emission reduction in China. Fortunately the society, government and enterprises have realized the importance of energy saving and emission reduction. The number and size of major energy Service Corporation is growing. According to incomplete statistics, as of the end of 2012, the number of the companies engaged in energy-saving 
services business reached to nearly 4175, an increase of $7 \%$ over the previous year. Employees over 430,000 people, an increase of $14 \%$ over the previous year, the energy conservation service industry output increase of $32.24 \%$. Among them, 3905 projects belong to that of contract energy management, total investment number was 50.572 billion yuan, an increase of $22.62 \%$ over the previous year, the implementation of energy saving was up to 17.7446 million tons of standard coal, 4430 tons of carbon dioxide emissions accordingly. Although it has made great achievements, but we should also clearly see, at present a lot of energy Service Corporation are difficult because of the difficult problem of financing, especially in some private energy Service Corporation. How to effectively solve the problem of financing difficulties, we need to create a new model. I hope it can help to solve the problem of financing energy Service Corporation by constructing financing mode of EMC and carbon emission combination.

\section{Research Status}

\subsection{Research on the EMC and Financing}

Much research has been done on the EMC mode, the existing problems and its application in various fields. Lu Zhijian and Sun Yuanxin make comparative analysis on four kinds of EMC mode: The Shared Savings Model, The Guaranteed Savings Model, The Leasing Model and BOOT. The EMC selection has been proposed: The Shared Savings Model is recommended to energy Service Corporation for a higher rate of return on investment, technology and bank credit; The Guaranteed Savings Model is recommended to energy Service Corporation for the accumulation of relevant project experience; The Leasing Model is recommended to energy Service Corporation for lack of funds and technology to be tested [1]. Xu Zhenyan and Guo Handing conducted a comparative study on the foreign EPC practice, the implementation of EPC is not only energy-saving building needs, but also the need to broaden the financing channels [2]. Yu Zhen, Wu Jianlin and Wei Xu in the field of building energy saving in China status of EMC, proposed the project scale, finance and energy consumption measurement and validation are major bottleneck restricting the EMC model in Chinese development. They proposed to explain the various elements of the whole the process of EMC in the form of building energy saving through the case [3].

\subsection{Research Based on the Carbon Emission Reduction and Carbon Trading}

Research on carbon emissions, carbon emissions accounting standard methodology and quota scheme of carbon emissions, carbon trading mechanism determined has been very thoroughly [4]. Zhuang Zhi and Hu Qiongqiong compared the terminal consumption carbon emission based on ISO14064 standards and based on the life cycle emissions standard of PAS2050, pointing the influence of boundary problem definition and factor of carbon emissions accounting. They pointed out that the domestic carbon emissions in the calculation of the reference, calculation method is not in line with international standards, and make the history data obtained from carbon emissions factor more difficult due to the regional differences in the economic development of our country. Therefore, in reference to international standards at the same time, it is necessary to develop China's carbon emission reduction accounting standards according to the actual data collection and a large number of case studies [4]. Tang Chengcai and Zhong Linsheng summed up relationship of energy consumption and carbon emissions from energy consumption and carbon emission measure, energy efficiency and carbon emission efficiency, energy intensity and carbon emissions intensity, energy consumption and carbon emission effect factors, energy consumption and carbon emissions scenario analysis of energy saving and emission reduction, put forward suitable research method system in each area and strengthen the research of service industry of energy consumption and carbon emission practice [5]. State Grid Energy Research Institute Jin Yanming predict coal power carbon dioxide emissions in different regions of China in 2015 and 2020 to consider the difference between the industrial structure, energy resources endowment characteristics, urbanization and the development of the technology level to suit one's measures to local conditions to develop emission reduction objective and promote the coordinated development of economy and environment in the area. Bettina made comparative study of the carbon tax system and the carbon emission trading system of emission reduction effect and economic effect. Ellerman made the implementation of total quantity control sulfur dioxide emission quotas to produce exchange mode. Zhang Maoqi and Lu Genfa made a classification research for the main carbon emission trading and showed financial characteristics of carbon markets. China carbon trading market is still in its infancy and do not establish the appropriate price system, many other causes of transaction price is significantly lower than the international carbon market price to strive for the right to determine the price of extremely unfavorable [6]. 


\subsection{Research about the EMC and Carbon Emission Reduction}

We have a lot of researches about these two aspects. But researches on the EMC and carbon trading of financing are few. Yuan Huajiang put forward the implementation of "property law" promulgated in our country on energy Service Corporation and contract energy management project financing effect [7]. Dai Jianru studied EMC project financing mode in the country such as USA and Brazil combined with the project financing of our country to design financing mode respectively for small EMC projects and large EMC project [8]. Shang Tiancheng presented financing mode by the demand side and energy-saving enterprises, which is better innovation, but have no carbon trading platform and lack of platform effect [9]. Zhang Yan's master's thesis into the design of EMC project financing mode of carbon emissions trading, give a more comprehensive and systematic research on the mode of binding with the EMC and carbon emissions trading by adding carbon emissions requirements side and innovatively use the real option pricing method [10].

To sum up, carbon emissions and EMC both at home and abroad is investigated theoretically in detail and effective practice. But it not have a clear and detailed discussion how will the carbon management and EMC in the aspects of policy, technology, investment and financing mechanisms combining, not to mention the carbon emissions trading system based on the construction of government, EMC, energy service companies, financial institutions, third party certification body.

\section{Feasibility Analysis of Financing Mode of Combination of EMC and Carbon Trading}

EMC is an energy-saving innovation pattern of technology, financing and management a market-energy-saving mechanism. Its essence is to reduce energy costs to pay for energy-saving projects cost. But it causes a series of problems of EMC project, because of consciousness, legal issues and policy oriented issues. So it has been in a embarrassing situation. Difficulties of financing and he project to find and credit evaluation system which is not perfect are three bottlenecks. Especially the financing difficult problem has seriously affected the sustainable development of energy service industry.

Carbon trading is a kind of new carbon emission reduction system. Emissions right or emissions quota is a "private property" which already exists before the energy-saving enterprises to achieve emission reduction targets. In the "total amount control and quota" emissions trading system, emission right is an existing "property" and the enterprise in the mandatory emission reduction system under "property". It is scarce, mandatory, exclusive and severable. Emission quotas for trading are parts of the initial allocation of emission quotas.

The trading index quantitative on the energy saving and carbon emission is equal to financial guarantee for EMC. It implement the pledge of EMC effectively joint the pledge of carbon emission rights. The integration system of carbon trading and EMC can effectively solve the difficult problem of financing.

Carbon trading and contract energy management are effective ways of energy saving and emission reduction. Because the EMC projects in general have the reduction effect, if the combination of the two, it is possible to carry out the improvement and innovation on existing EMC project financing and operation mode. If the carbon trading ideas and mode of project are embedded into the EMC project through the unity of energy saving and emission reductions, we can put the carbon rights pledge of EMC as a channel of financing, which implement the pledge of EMC effectively joint the pledge of carbon emission rights. It not only can active carbon trading market mechanism, and can solve the difficult problem of financing of EMC.

Energy saving service companies often directly or indirectly produced the effect of emission reduction. Carbon emission reduction benefits as a right to mortgage financing receivables. Through the analysis of the carbon emission reduction quotas and index market we preliminary study combination model of EMC project energy saving and carbon emissions trading market. Using the pledge of EMC to effectively joint the pledge of carbon emission rights can promote the EMC project and solve the difficult problem of financing.

\section{The Construction of Integrated Financing System of EMC and Carbon Trading}

The carbon emission reduction audit standard and thought put into EMC project in the amount of energy saving, which makes EMC project monitoring, reporting, verifiable, transactional. We can design the carbon emissions trading system as graph based on the construction of government, EMC, energy service companies, financial institutions, third party certification body (Figure 1). 


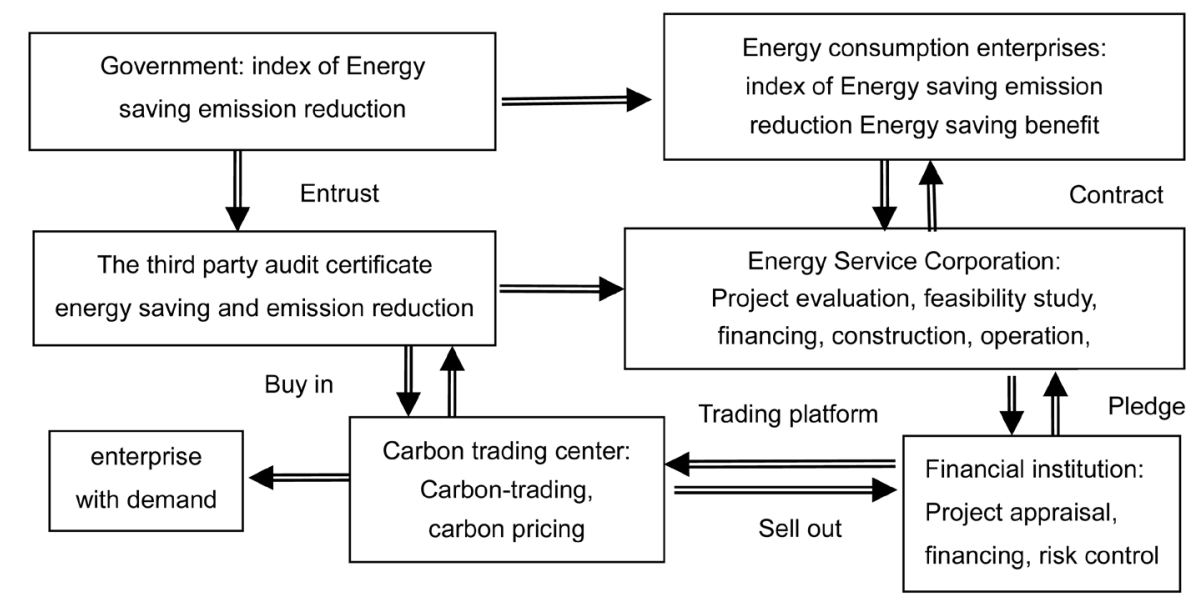

Figure 1. Integrated financial platform of EMC and carbon trading.

\subsection{The Relevant Departments of Government}

The government make the total control of emission reduction targets based on energy consumption enterprises historical emissions data as well as the original targets and issue energy-saving and emission reduction quotas combined with the production scale, production quality and harmful emissions, which also need support of the fiscal and tax policies.

\subsection{Energy Consumption Enterprises}

Energy enterprises make target according to energy-saving and emission reduction index, adjust the production and take various measures to complete the target. On one hand, energy consumption enterprises account cost benefit, on the other hand, reasonable arrangements is made for the main industry and sideline. In addition to the structural adjustment and technological innovation, energy saving and emission reduction projects which are not good for the EMC should sign a contract with the energy professional company and complete of the emission reduction targets through the contract way.

\subsection{Energy Service Companies}

Energy Service Companies are professional companies engaged in energy-saving and emission reduction. They sign contract with energy companies through technology, equipment and design expertise. They are in charge of project evaluation, feasibility study, project financing, project construction, project management and project transformation. Energy Service Companies get benefit from income of customer service and give it to energy companies after a certain age.

\subsection{Financial Institution}

Financial institutions including commercial banks, fund and international financial organizations pledge loans to energy company based on pledge of carbon emission rights and income right and give project evaluation, financing payment and risk control.

\subsection{The Third Audit Party}

The third audit party institutions give certification by certifying energy saving and emission reduction and through certain conversion methods of energy savings and carbon emission reduction. Energy service companies or financial institutions trade in the carbon trading center according to the state price and sell it to the government or the enterprises to achieve revenue.

\subsection{Carbon Trading Center}

Government sets up a carbon trading center in charge of construction of platform, rules, system and network to 
provide convenient and fast service for carbon trading.

The above organizations under the guidance of national policy and the combination of pledge of carbon emission rights and income right build an integrated financing mode. The design of this model will create a win-win situation to reduce the administrative costs, to help the energy consumption enterprises energy-saving and emission reduction, to solve the financing dilemma, undertake energy-saving projects smoothly and raise benefits and to help financing institutions to find a sustainable investment projects.

\section{Safeguard Measures}

\subsection{To Further Clarify the Total Carbon Emissions and Carbon Emissions Quota}

In certain regions and periods, emission right can be traded with trading volume of carbon. It is a little difficult to design not too low or high. It needs an in-depth research for total carbon emissions. It forms verification mechanism and principle of stable carbon emission combined with the total energy consumption target, carbon reduction target and GDP growth parameters.

\subsection{To Establish and Perfect Mechanism of Carbon Monitoring and Regulation}

We should build balance account as soon as possible to collect and pay the carbon fund and ecological compensation. But the premise is professional, fair, government approved third party to certificate carbon emissions and conversion method.

\subsection{To Set up the Nationwide Mechanism of Carbon Trading Market and Exchange}

We should set up the trading market combination of entity and virtual to provide convenient and fast trading place for members and participants. We also pay attention to the construction of infrastructure, strengthen the exchange and learning with the developed countries and actively participate in trading rules of international carbon.

\subsection{To Encourage a Group of Professional Third Party Monitoring Agency with Strict Standard}

The smooth implementation of carbon trading and carbon right certification is premises. Therefore, the fair, justice and public third party monitoring mechanism needs to continue to build.

Financial institutions need reformation and innovation of financial service mode. We also need to cultivate professional talents with carbon trading and do risk assessment precisely.

Of course, to achieve the financing models of integration of EMC and carbon rights needs a lot of work of consciousness, policy, mechanism and operational procedures and information network. But it will make a great contribution once it is implemented for the energy conservation and emission reduction in China.

\section{Funding}

Funded by the national natural fund project (61203148) and DSM pilot cities performance evaluation research project.

\section{References}

[1] Lu, Z.J. and Sun, Y.X. (2012) Study on Foreign Contract Energy Management and Suggestions to China. Science and Technology Management Research, 2012, 39-42.

[2] Xu, Z.Y., Guo, H.D. and Ren, S.M. (2008) Review of Domestic and Foreign Contract Energy Management Theory and Practice. Building Economy, 2008, 100-103.

[3] Yu, Z., Wu, J.L. and Xu, W. (2012) Constract Energy Management in the Field of Construction Saving Energy. Building Science and Technology, 2012, 1-7.

[4] Zhuang, Z., Hu, Q.Q., Zhu, W.F., Xu, Q. and Tan, H.W. (2012) Current Situation and Discussion of the International Carbon Emission Accounting Standards. Low Carbon Communities and Green Building, 2012, 412-415.

[5] Tang, C.C., Zhong, L.S. and Sheng, S.K. (2012) Research Developing of Energy Consumption and Carbon Emission in 
Service Industry. China Population Resource and Environment, 2012, 390-395.

[6] Zhang, M.Q. and Lu, G.F. (2009) Carbon Trading Market Mechanism Analysis. Environmental Protect, 412, 77-81.

[7] Yuan, H.J. (2009) EMC Project Financing Mode in Era of Property Law. International Finance, 2009, 30-36.

[8] Dai, J.R. (2006) Financing Mode Research of EMC in China. Central University of Finance and Economics, Beijing.

[9] Shang, T.C. and Gao, J.Q. (2012) Construction of EMC Project Financing Mode of Surplus Emission Quota. Journal of Tianjin University (Social Science Edition), 14, 7-12.

[10] Zhang, Y. (2010) The Design of Financing Mode with EMC Project of Carbon Emissions Trading. Master's Thesis, Tianjin University, Tianjin. 
Scientific Research Publishing (SCIRP) is one of the largest Open Access journal publishers. It is currently publishing more than 200 open access, online, peer-reviewed journals covering a wide range of academic disciplines. SCIRP serves the worldwide academic communities and contributes to the progress and application of science with its publication.

Other selected journals from SCIRP are listed as below. Submit your manuscript to us via either submit@scirp.org or Online Submission Portal.
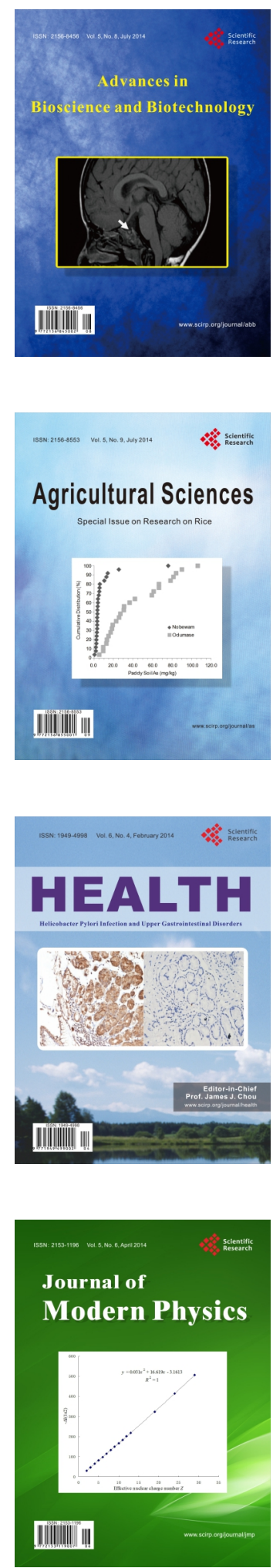
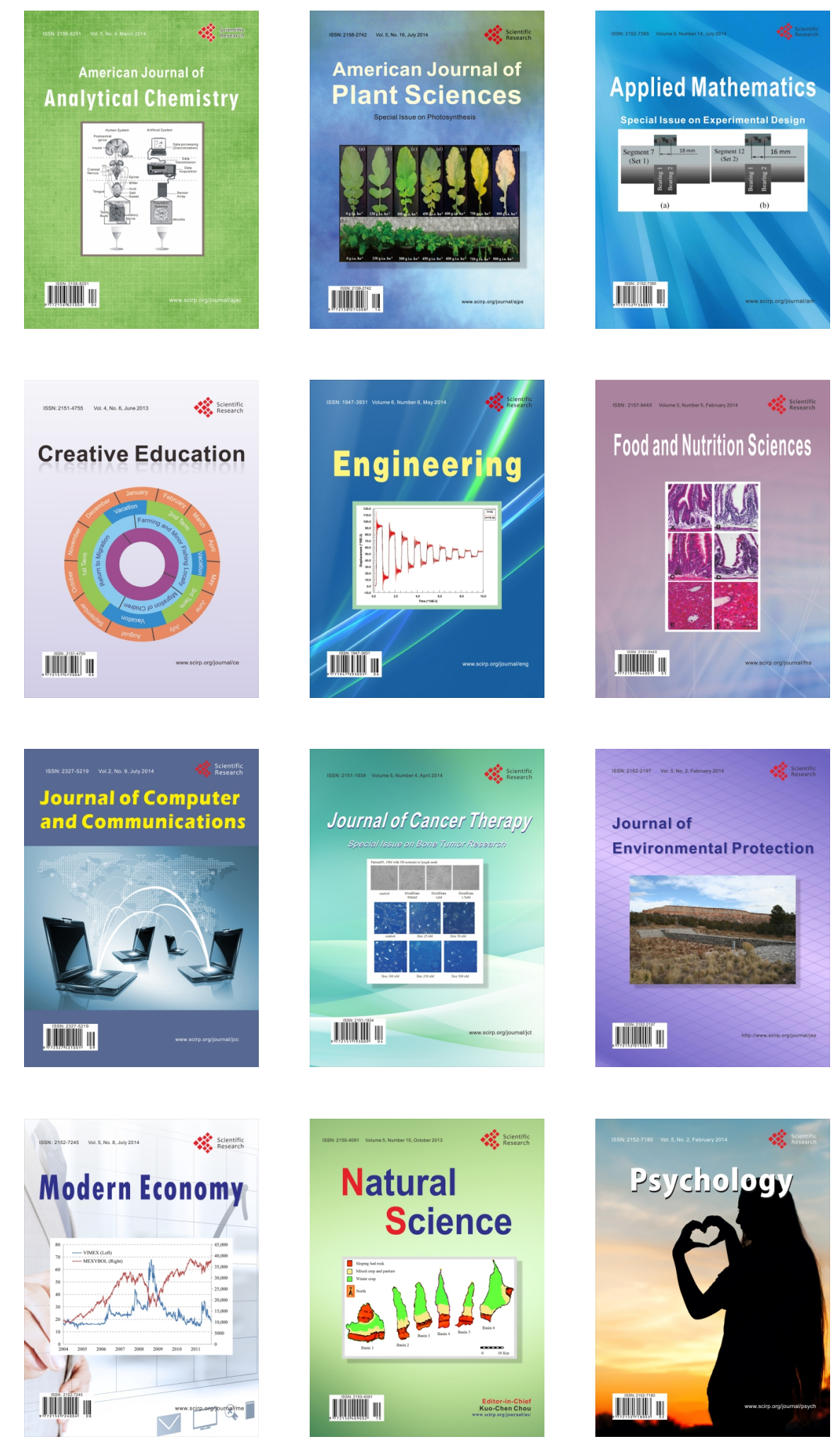